\title{
'||||||||||||||||||||||||||||||||||||||||||||||||||||||||||||||||||.
}

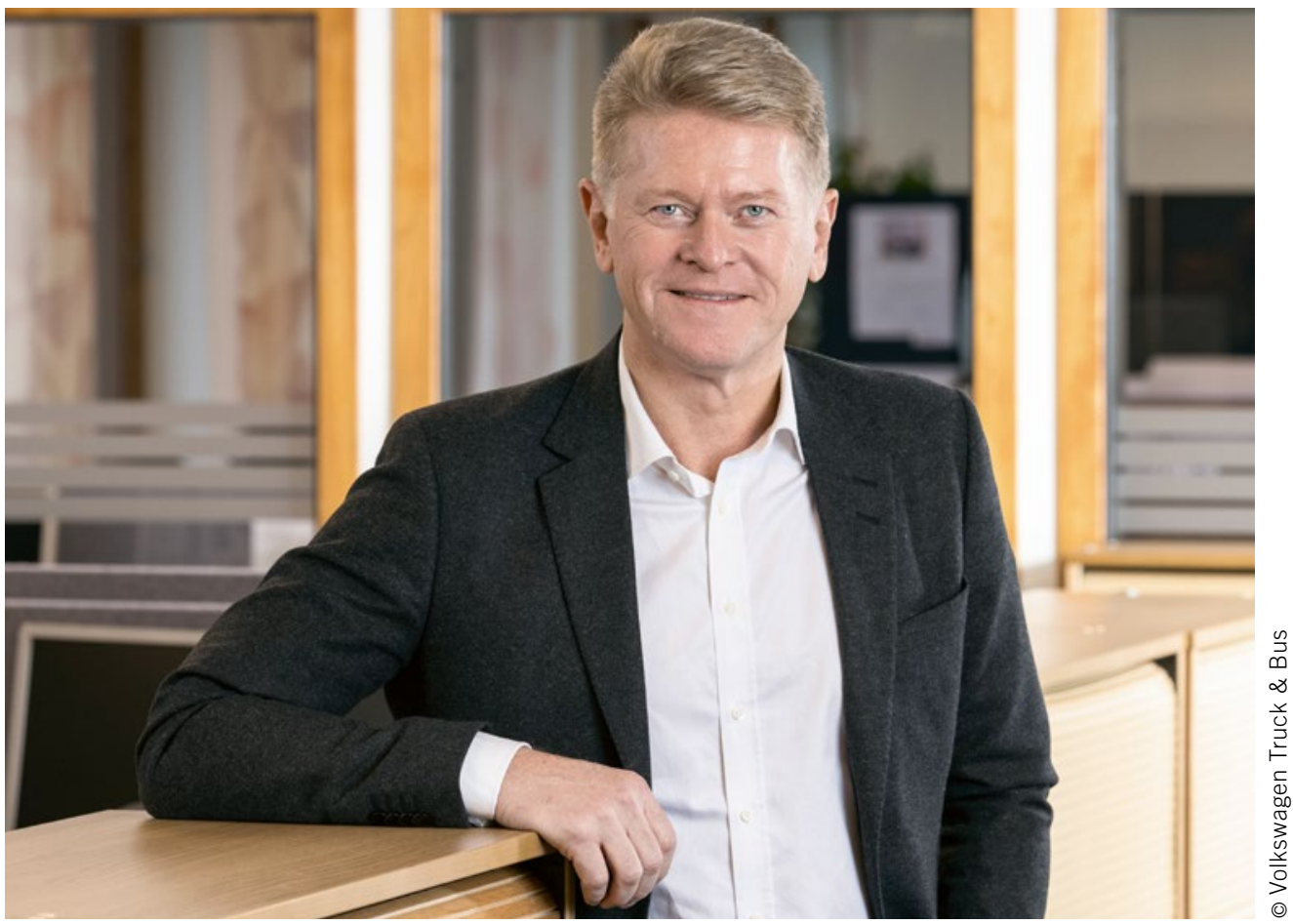

Anders Nielsen, M. Sc. Chief Technical Officer bei Volkswagen Truck \& Bus

\section{Die Zukunft des Verbrennungsmotors}

Das Ende des Verbrennungsmotors steht vor der Tür, wenn man Medienberichten glauben darf. Unbestritten ist: Die aktuelle Debatte um die Stickstoffoxidbelastung in deutschen Städten erhöht die Notwendigkeit, Emissionen zu senken. Das gleiche gilt für die erwarteten EU-Vorschriften, den $\mathrm{CO}_{2}$-Ausstoß von schweren Nutzfahrzeugen zu reduzieren. Ich plädiere für eine positive Sichtweise: Unsere Industrie hat die Chance, zur Verbesserung der Lebensqualität beizutragen. Ich sehe es ganz klar als unsere Aufgabe an, für jede Anwendung eine möglichst nachhaltige Lösung zu bieten. Lösungen, die sich durch Effizienz und Zuverlässigkeit auszeichnen. Dabei wird oft übersehen, dass unsere Branche schon heute Alternativen anbietet, die im Vergleich zum Dieselmotor niedrigere Emissionen aufweisen.

Tatsächlich wurde mit Euro VI für Diesel-Lkw bereits ein sehr niedriger Ausstoß an Emissionen erreicht. Und mit alternativen Kraftstoffen wie Biodiesel, E-Fuels und LNG sind weitere Reduzierungen möglich. Gerade LNG, das beispielsweise in Italien seit Jahrzehnten ein beliebter Kraftstoff ist, bietet Vorteile: bis zu $15 \%$ weniger $\mathrm{CO}_{2}$-Ausstoß als beim Diesel, kaum Feinstaub und $\mathrm{NO}_{\mathrm{x}}$-Emissionen. Mehrere Nutzfahrzeughersteller, darunter Scania in Kooperation mit der Volkswagen Konzernlogistik, arbeiten an LNG-Lösungen für den Fernverkehr. CNG wiederum hat sich schon seit vielen Jahren als Alternative bei Stadtbussen etabliert. In diesem Segment ist MAN mit rund $40 \%$ Marktanteil führend in Europa. Ein weiteres Argument für den Verbrennungsmotor ist seine hohe Eignung für den Fernverkehr, Baustellenfahrzeuge und den Einsatz in schwierigem Gelände. Während im Fernverkehr Reichweiten von mindestens tausend Kilometern absolut notwendig sind, spielt bei Offroad der hohe Energiebedarf eine entscheidende Rolle. Ein elektrischer Antrieb kommt hier schnell an seine Grenzen, was die Reichweite betrifft. Daher kommt dem Verbrennungsmotor als Brückentechnologie eine große Bedeutung zu.

Bis elektrisch betriebene schwere Nutzfahrzeuge in großen Stückzahlen in Europa im Einsatz sind, dürfte es also noch einige Zeit dauern. Dennoch eignen sich elektrische Antriebe durchaus für verschiedene Anwendungen. Dazu zählen zum Beispiel CityBusse mit klar definierten Routen und Standzeiten. Aber auch Transporter für die letzte Meile und mittlere bis schwere Verteiler-Lkw, die nicht mehr als $200 \mathrm{~km}$ pro Tag zurücklegen. Ich bin daher fest überzeugt, dass elektrische Antriebe in diesen Anwendungen eine große Zukunft haben. Der technologische Fortschritt und steigende Stückzahlen werden dafür sorgen. Ich gehe künftig von einem Nebeneinander unterschiedlicher Antriebsformen aus. Das wird zur Senkung der Emissionen beitragen und die urbane Lebensqualität erhöhen. Für die Hersteller stellt die aktuelle Entwicklung eine außergewöhnliche Herausforderung dar: Sie müssen Dieselantriebe weiter verbessern, gleichzeitig Verbrennungsmotoren mit alternativen Kraftstoffen optimieren und elektrische Antriebe zur Marktreife bringen. 